\title{
Vascular responses in the hands of patients suffering from migraine
}

\author{
J. A. DOWNEY ${ }^{1}$ AND D. B. FREWIN \\ From the Department of Human Physiology and Pharmacology, \\ University of Adelaide, South Australia
}

SUMMARY The response of the hand blood vessels to a measured, controlled cold stimulus was determined, using venous occlusion plethysmography, in normal subjects and patients who sufferedo from migraine. The resting level of hand blood flow was found to be higher in the patients, but the percentage fall in flow that resulted when the cold stimulus was applied was less than in the normal: subjects. The hand blood vessels of the patients responded to intra-arterial noradrenaline and $\vec{\omega}$ tyramine in a normal fashion.

Migraine is thought to result from a vasomotor disturbance within the distribution of the common carotid artery (Brain, 1962), consisting initially of arterial spasm followed by dilatation. Engel, Ferris, and Romano (1945) observed evidence of cortical ischaemia during the scotomatous phase of the attack, and Schumacher and Wolff (1941) found that amyl nitrite could temporarily abolish the scotomata. These observations support the suggestion that arterial spasm is responsible for the visual disturbances and other cortical symptoms at the onset of an attack of migraine.

The headache in migraine is due to dilatation mainly of the extracerebral arteries of the dura mater and scalp-that is, branches of the external carotid artery (Schumacher and Wolff, 1941), and the therapeutic effect of ergotamine tartrate on the headache is thought to be due to its vasoconstricting effect (Brain, 1962).

Hanington and Harper (1968) suggested that in some patients migraine is precipitated by ingestion of certain foodstuffs which results in an excess of tyramine in the blood stream releasing noradrenaline from the tissues and causing selective cerebral vasoconstriction and a generalized extracerebral vasoconstriction. It was postulated that when the tissue stores of noradrenaline were exhausted, rebound vasodilatation occurred affecting mainly the extracerebral vessels, resulting in headache.

1 Present address: Department of Rehabilitation Medicine, College of Physicians and Surgeons of Columbia University, 630 West 168th Street, New York, N.Y. 10032. U.S.A.
It seems possible that this form of vasculat response might not be limited to the craniaf circulation of migraine sufferers, and there is evidence that these patients have a general dis은 order in the control of blood vessels (British Medical Journal, 1964). The capillaries in thes nail folds of migraine sufferers have been fougd: to be abnormal (Hauptmann, 1946), a Appenzeller, Davison, and Marshall (19庅N reported a lack of reflex vasodilatation in the hands of migraine patients in response to bodys heating.

In the study reported here, the blood flow: through the hands of patients with migraine was measured and the response to cooling of on $\overrightarrow{\vec{s}}$ hand compared with that of normal subjects. In addition, in some of the patients, the response of the hand vasculature to intra-arterially adminis tered noradrenaline and tyramine was tested in an attempt to assess the sensitivity of thi? vascular bed to these vasoactive substances.

\section{METHODS}

The subjects for these studies were eight norma volunteers and five patients suffering from migraineo A brief summary of the clinical characteristics of the subjects is given in Table 1.

The experiments were carried out at laboratoro temperatures ranging from 29 to $32 \cdot 5^{\circ} \mathrm{C}$, with variation of not more than $1^{\circ} \mathrm{C}$ in each experiment ${ }_{-}$ The subjects lay recumbent on a couch for at least $3 \&$ minutes before observations were made, during which time the recording apparatus was applied. Im all cases, a minimum of two hours had elapsed since 
TABLE 1

CLINICAL CHARACTERISTICS OF CONTROL SUBJECTS AND PATIENTS

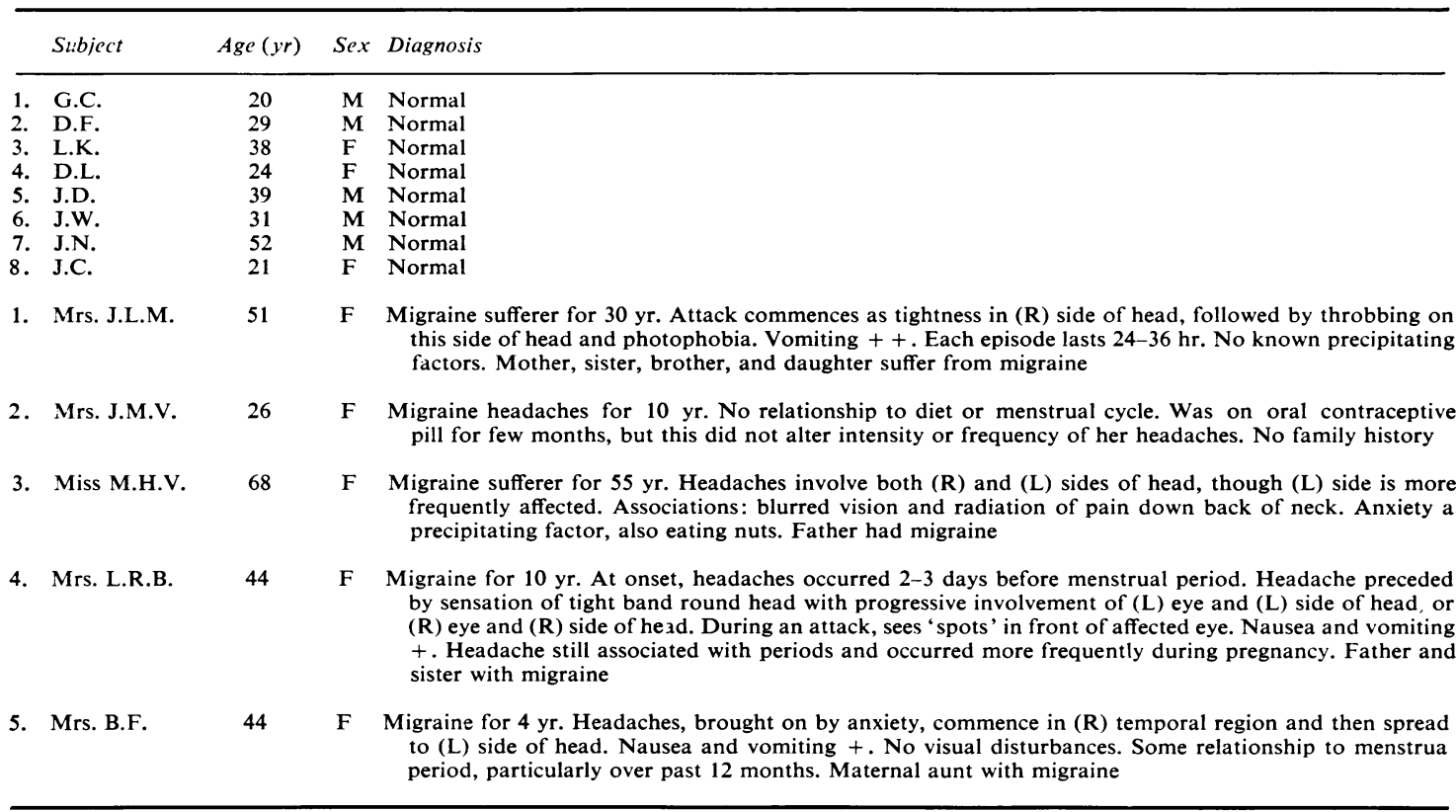

the last meal or cigarette. All drug therapy was suspended for at least a week before testing.

Hand blood flow was measured by venous occlusion plethysmography, using water-filled plethysmographs initially maintained at a temperature of 32 $33^{\circ} \mathrm{C}$ (Greenfield, 1954), three or four records of flow being obtained each minute. After recordings had been made at this temperature, the water in the plethysmograph on the right (treated) hand was rapidly aspirated and replaced with colder water at a preselected temperature. This procedure took approximately one minute. Six minutes later the cold water was aspirated and replaced with water to return the temperature of the plethysmograph to $32^{\circ} \mathrm{C}$. The water temperature in contact with the hand was recorded just before aspiration. Three cooling periods of different intensities were administered to each subject in a randomized pattern. In two of the subjects, the cooling was repeated on a second day to check the reproducibility of the results and the responses were found to agree within $\pm 4 \%$.

The effects on hand blood flow produced by the cold were determined from the averaged flow values during the two minutes before the stimulus was applied and the fifth and sixth minutes of contact of the hand with the cool water. The absolute and percentage falls in flow on both the treated and untreated sides were calculated. In addition, the percentage fall of the treated hand was adjusted by subtraction of changes in the contralateral hand so as to correct for systemic effects produced by the cold and also spontaneous fluctuations unrelated to cold (Duff, 1952). The changes in flow were then plotted against the final water temperature producing the fall. The time taken for the blood flow to recover to resting levels on both the treated and untreated sides was also determined. These results were plotted in a similar fashion.

The sensitivity of the hand blood vessels to noradrenaline and tyramine were tested in some of the patients. Intra-arterial infusions of the drugs of four or five minutes' duration were given into the brachial artery at the elbow of one arm through a 22 or 23 gauge needle connected by a length of polyethylene tubing to a mechanically driven syringe which delivered $2 \mathrm{ml}$. of solution per minute. Saline $(0.9 \% \mathrm{w} / \mathrm{v})$ was infused during the control periods and also used as a vehicle for the drugs. The doses of drugs used were such that they did not produce systemic effects, thereby making it possible to use the opposite uninfused limb as a control.

Percentage changes in hand blood flow produced by noradrenaline and tyramine were determined from the averaged flow values during the two minutes before the drug infusion and the last two minutes of the infusion period, by which time the responses to the drugs had become stable. Allowance was made for spontaneous variations in flow unrelated to drug action by assuming that in the absence of the drug infusion, the infused and control sides would have maintained the same relationship to each other as in the pre-infusion period (Duff, 1952).

The drugs used were noradrenaline bitartrate monohydrate (Levophed, Winthrop) and tyramine 
hydrochloride (Koch-Light Laboratories Ltd). The doses of noradrenaline are expressed as weights of the base and those of tyramine as weights of the salt. Ascorbic acid $(1: 50,000)$ was added to the noradrenaline solutions.

\section{RESULTS}

The eight normal subjects had a mean initial hand blood flow of $10.7 \mathrm{ml} . / 100 \mathrm{ml} . / \mathrm{min}$ (SEM 0.828 ) and the patients one of $13.5 \mathrm{ml} . / 100 \mathrm{ml}$./ min (SEM 1.22) (Table 2). Statistical comparison of these results showed that the higher flow in the migraine subjects lay between the $0 \cdot 1$ and 0.05 level of significance.

Percentage fall in flow is used to make it possible to compare changes in flow in subjects with differing initial blood flows (Cooper, Fewings, Hodge, and Whelan, 1963). Figure 1 shows the corrected percentage falls in hand blood flow of the cooled hand in eight normal subjects, as well as the calculated regression line for the plotted values. The latter has the equation:

Per cent fall in hand blood flow

$$
\begin{aligned}
& =143.8-4.95 \\
& \times\left(\text { Final plethysmograph temp. }{ }^{\circ} \mathrm{C}\right) \\
& r=0.865 \quad(\mathrm{P}<0.001)
\end{aligned}
$$

Figure 2 shows the corrected percentage falls in blood flow of the cooled hands in the five patients suffering from migraine. The regression line for these responses is shown as well as the regression line of the normal subjects. The former line has the equation:

Per cent fall in hand blood flow

$$
\begin{aligned}
& =109.9-3.83 \\
& \times\left(\text { Final plethysmograph temp. }{ }^{\circ} \mathrm{C}\right) \\
& r=0.77 \quad(\mathrm{P}<0.001)
\end{aligned}
$$

TABLE 2

AVERAGED INITIAL HAND BLOOD FLOW OF EACH OF EIGHT NORMAL SUBJECTS AND FIVE PATIENTS

\begin{tabular}{llc}
\hline & Subject & Flow $(\mathrm{ml} . / 100 \mathrm{ml} / \mathrm{min})$ \\
\hline 1. & G.C. & 10.6 \\
2. & D.F. & 9.1 \\
3. & L.K. & 7.4 \\
4. & D.L. & 12.1 \\
5. J.D. & 6.4 \\
6. & J.W. & 6.9 \\
7. & J.N. & 14.4 \\
8. & J.C. & 19.7 \\
& & 16.1 \\
1. & Mrs. J.L.M. & 16.4 \\
2. & Mrs. J.M.V. & 11.9 \\
3. & Miss M.H.V. & 16.8 \\
4. & Mrs. L.R.B. & 6.2 \\
5. & Mrs. B.F. & \\
\hline
\end{tabular}

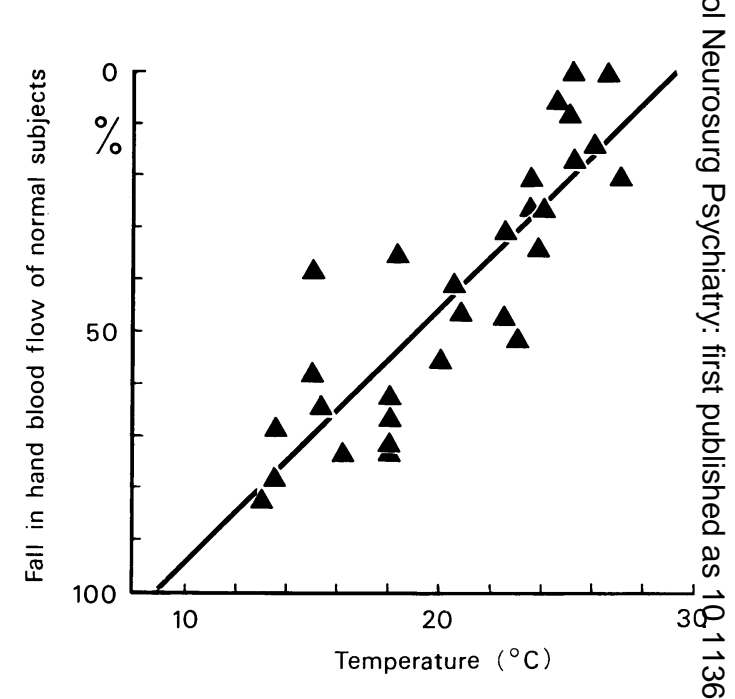

FIG. 1. The corrected percentage falls in hand bloo flow of eight normal subjects in response to cooling? plotted against the final temperature of the water itw the plethysmograph producing the fall. The calculated regression line for the points is shown.

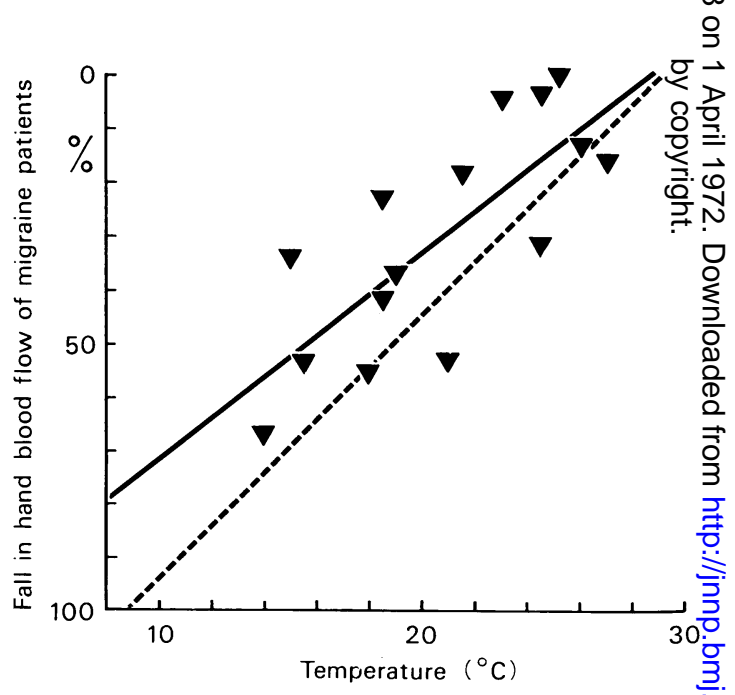

FIG. 2. The corrected percentage falls in hand bloods flow of the migraine patients plotted against the fina $\bar{R}$ water temperature producing the fall in flow. The solid line is the regression line for the patients and the broken line that for the normal subjects.

Although there is no significant differencê between the slopes of the regression lines, the intercepts of these are significantly differen (Table 3) $(\mathrm{P}<0.05)$, and this indicates that, in the patients, the corrected percentage fall in hand blood flow in response to the application? of a cold stimulus is less at all temperatures.0 
TABLE 3

REGRESSION OF PERCENTAGE FALL IN HAND BLOOD FLOW AGAINST TEMPERATURE $\left({ }^{\circ} \mathrm{C}\right)$

\begin{tabular}{|c|c|c|c|c|c|c|c|c|}
\hline Treatment & $\begin{array}{c}\text { Observations } \\
\text { (no.) }\end{array}$ & $\begin{array}{l}\text { Intercept } \\
(A)\end{array}$ & $\begin{array}{c}\text { Standard } \\
\text { deviation }(A)\end{array}$ & $\begin{array}{c}\text { Statistical } \\
\text { significance }\end{array}$ & $\begin{array}{l}\text { Slope } \\
(B)\end{array}$ & $\begin{array}{c}\text { Standard } \\
\text { deviation }(B)\end{array}$ & $\begin{array}{c}\text { Statistical } \\
\text { significance }\end{array}$ & Regression \\
\hline $\begin{array}{l}\text { Migraine } \\
\text { Normal } \\
\text { Pooled } \\
\text { regression }\end{array}$ & $\begin{array}{l}15 \\
29 \\
44\end{array}$ & $\begin{array}{l}109 \cdot 9611 \\
143 \cdot 8262 \\
133 \cdot 5482\end{array}$ & $\begin{array}{l}\left.\begin{array}{l}18 \cdot 8593 \\
11 \cdot 5574 \\
10 \cdot 5630\end{array}\right\}\end{array}$ & $\begin{array}{c}<0.05 \\
-\end{array}$ & $\begin{array}{l}-3 \cdot 8375 \\
-4.9541 \\
-4.6323\end{array}$ & $\begin{array}{l}0.8921 \\
0.5509 \\
0.5022\end{array}$ & $\overline{-}$ & $\begin{array}{l}-0.7664 \\
-0.8658 \\
-0.8182\end{array}$ \\
\hline
\end{tabular}

Figure 3 shows the actual fall in hand blood flow ( $\mathrm{ml} . / 100 \mathrm{ml} . / \mathrm{min}$ ) on the cooled side during the fifth and sixth minutes of cooling, plotted against the temperature of water in the plethysmograph. The changes in flow clearly overlap, indicating that the total fall in flow of the patients is not different from the normals.

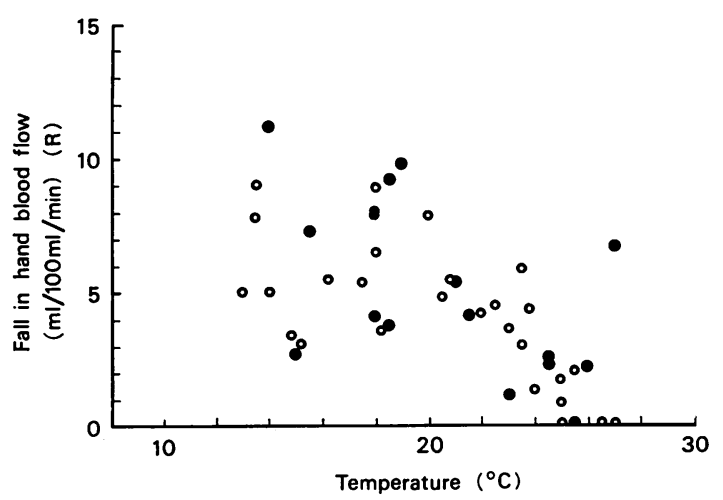

FIG. 3. The actual falls in hand blood flow (ml.) $100 \mathrm{ml} . / \mathrm{min})$, plotted against the final water temperature. patients; $\bigcirc$ normal subjects.

Reflex vasoconstriction occurred in the control hand in response to cooling. The percentage falls in flow on the control side during the cooling were the same in the patients as in the normal subjects, and the time for the flow to return to resting level after the cooling was stopped was similar for both groups.

The sensitivity of the hand blood vessels to noradrenaline was measured in three patients and found to be within the normal range. Figure 4 shows the results from a typical study in one patient in which the percentage falls in hand flow resulting from the intra-arterial infusion of 50, 100 , and $200 \mathrm{ng}$ noradrenaline per min for four minutes are presented. The hatched areas in the Figure include one standard deviation about the mean responses obtained for the respective dose of each drug in normal subjects. In two patients, the responses of the hand vasculature to doses of

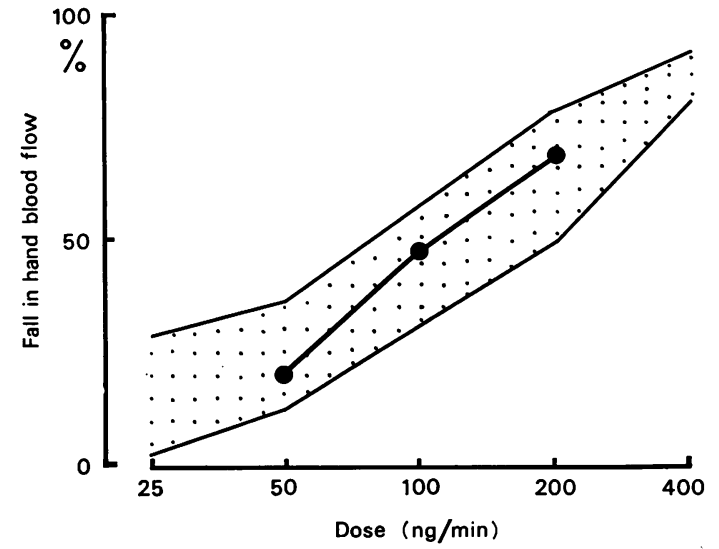

FIG. 4. The hatched area includes one standard deviation about the mean response for each of five doses of noradrenaline. The superimposed dose response curve (-) was constructed from the percentage falls in hand blood flow in response to the intra-arterial infusion of noradrenaline in one patient.

50 and $100 \mu \mathrm{g}$ intra-arterial tyramine administered for five minutes also fell within the normal range.

\section{DISCUSSION}

The mean resting blood flow in the hands of four of the migraine patients was higher than that in the normal subjects. This observation is in accord with others. French, Lassers, and Desai (1967) measured hand flow in a warm room, and found a mean basal hand flow of $13.1 \mathrm{ml}$./ $100 \mathrm{ml} . / \mathrm{min}$ in the migraine sufferers and $12.3 \mathrm{ml} . / 100 \mathrm{ml} . / \mathrm{min}$ in the normals. In the study performed by Appenzeller et al. (1963), which was conducted at an ambient temperature of 24 to $26^{\circ} \mathrm{C}$, the mean basal hand blood flow was $8.4 \mathrm{ml} . / 100 \mathrm{ml} . / \mathrm{min}$ in the patients and $7.7 \mathrm{ml} . / 100 \mathrm{ml} . / \mathrm{min}$ in the normal subjects. A statistical analysis of this data was not made by the respective authors.

When the right hand of the patients was subjected to a measured cold stimulus, the resultant corrected percentage fall in flow was significantly 
less than in the normal subjects. Correcting the percentage fall in flow eliminates the systemic effects produced by the cold and also spontaneous fluctuations in hand blood flow. The corrected result therefore represented the direct local effect of the cold stimulus on the hand blood vessels. These results would indicate a diminished reactivity of the vessels to cold in the patients with migraine.

When the absolute falls in flow of the cooled hand were compared, the patients and the normal subjects were found to have similar values. However, as the initial level of flow in the patient group was higher, a normal absolute fall in flow superimposed on this higher initial flow resulted in a smaller percentage constriction. The response of the hand vessels of the uncooled hand was similar both in terms of percentage fall in flow and the time taken for the circulation to recover after the removal of the cold stimulus. These results indicate that the systemic response to cold in the patients was not abnormal.

The reason for the higher basal hand flows in the patients is not clear. One possibility is that the resting sympathetic tone of the hand blood vessels is less than in the normal subjects. Adams, Orton, and Zilkha (1968) have studied temporal arteries obtained from patients during an acute attack of migraine and found that the tunica adventitia of these vessels has a marked capacity to bind noradrenaline. They suggest that such adventitial catecholamine-binding may prevent noradrenaline from acting on the vascular smooth muscle and this leads to dilatation in the temporal artery. Histochemical studies of this nature have not been carried out on the digital arteries of migraine sufferers, but if adventitial catecholamine-binding also occurred in these vessels, it would tend to diminish the constrictor responses to tyramine. In both subjects, however, the vascular response to this agent fell within the normal range and the result does not therefore favour this hypothesis.

Another possibility is that there is a diminished sensitivity of the vascular smooth muscle. The nature of this defect, whether it is intrinsic in the blood vessels or due to a circulating vasodilator substance, is not apparent. The responses of the hand vasculature to cold which are described in this study are similar to those seen in normal subjects who have ingested alcohol (Downey and Frewin, 1970). Patients with migraine can respond to vasoconstrictor agents such as nor- adrenaline and tyramine in a normal fashion The constrictor effect of tyramine in man has been shown to be dependent on the presence of sympathetic nerves (Frewin and Whelan, 1968\%, and a normal response to this substance points to the integrity of the sympathetic innervation The responses of the hand vasculature to nore adrenaline in terms of percentage fall in flow and duration of constrictor response were normal ane substantiate the conclusion of an intact sympa thetic innervation to this vascular bed.

Patients also respond to emotional stress wit

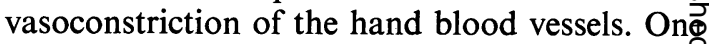
patient (Mrs. B.F.) had an initial hand bloo flow of $6.2 \mathrm{ml} . / 100 \mathrm{ml} . / \mathrm{min}$. This was one of the lowest flow values recorded during the series an was probably due to the fact that she was ver apprehensive during the study. The increased sympathetic discharge which resulted due to het anxiety would have been responsible for the diminished hand blood flow. It is of interest thaif in this patient episodes of migraine were precipiv tated by anxiety and the fact that two hours afteso the experiment she developed a typical migrain\& headache. One other subject (Miss M.H.V.) \& $\mathbb{\Psi}_{\mathrm{s}} \sigma$ implicated anxiety as a precipitating factor ar she, too, had a lower resting blood flow than $\frac{\varphi_{h}}{2}$ other patients.

Rompel and Bauermeister (1970), in a recent paper on the aetiology of migraine, conside emotional stress to be a definite factor in $89.5^{\circ} \%$ of all the cases they reviewed. They found the patients who suffered from migraine were of the tense, anxious type with 'a depressive or conf stricted personality'. Hanington and Harpes (1968) have suggested that migraine could resulf from the release of sympathetic neurotran mitter from the nerve endings by substances, suck as tyramine, which cause exhaustion of the tissue stores of noradrenaline and rebound vasodilatis tion. It could be postulated that in anxious. individuals, who have an increased sympathet discharge and therefore a diminished store $\overline{\text { of }}$ noradrenaline, the sudden entry of an indirectlo acting sympathomimetic agent, like tyramines into the blood stream could result in the rapia release of transmitter, causing depletion of the nerves and rebound vasodilatation. This theory does not, however, elucidate the mechanism of headache in the group who have a high initigip level of flow and a normal sympathetic innerva tion of these blood vessels. In these individuals other factors, such as changes in the plasm serotonin level, may have to be invoked to 
explain the occurrence of their migraine headaches.

Our thanks are due to Professor R. F. Whelan for suggesting this investigation and for his advice and encouragement throughout. We are grateful to Dr. D. P. Finnegan and Dr. J. M. Bonnin for permitting us to study their patients, and Mr. W. B. Taylor of the Department of Statistics, University of Adelaide, for help with the analysis of results. Mrs. J. Cooper, Mrs. L. L. Kingston, and Mrs. M. Wilkins provided expert technical assistance. This work was supported in part by a research grant from the National Health and Medical Research Council of Australia to Professor R. F. Whelan. One of us (J.A.D.) was supported in part by the Chichester-Dupont Foundation and Burroughs Wellcome.

\section{REFERENCES}

Adams, C. W. M., Orton, C. C., and Zilkha, K. J. (1968). Arterial catecholamine and enzyme histochemistry in migraine. Journal of Neurology, Neurosurgery, and Psychiatry, 31, 50-56.

Appenzeller, O., Davison, K., and Marshall, J. (1963) Reflex vasomotor abnormalities in the hands of migrainous subjects. Journal of Neurology, Neurosurgery, and Psychiatry, 26, 447-450.

Brain, Lord (1962). Diseases of the Nervous System, 6th edition, pp. 243-250. Oxford University Press: London.

British Medical Journal (1964). Leading article. Vascular response in migraine. British Medical Journal, 1, 195-196.

Cooper, C. J., Fewings, J. D., Hodge, R. L., and Whelan, R. F. (1963). Effects of bretylium and guanethidine on human hand and forearm vessels and on their sensitivity to noradrenaline. British Journal of Pharmacology and Chemotherapy, 21, 165-173.

Downey, J. A., and Frewin, D. B. (1970). The effect of ethyl alcohol and chlorpromazine on the response of the hand blood vessels to cold. British Journal of Pharmacology, 40, 396-405.

Duff, R. S. (1952). Effect of sympathectomy on the response to adrenaline of the blood vessels of the skin in man. Journal of Physiology, 117, 415-430.

Engel, G. L., Ferris, E. B., Jr., and Romano, J. (1945). Focal encephalographic changes during scotomas of migraine. American Journal of Medical Science, 209, 650-657.

French, E. B., Lassers, B. W., and Desai, M. G. (1967). Reflex vasomotor responses in the hands of migrainous subjects. Journal of Neurology, Neurosurgery, and Psychiatry, 30, 276-278.

Frewin, D. B., and Whelan, R. F. (1968). The mechanism of action of tyramine on the blood vessels of the forearm in man. British Journal of Pharmacology and Chemotherapy, 33, $105-116$.

Greenfield, A. D. M. (1954). A simple water-filled plethysmograph for the hand or forearm with temperature control. Journal of Physiology, 123, 62-64P.

Hanington, E., and Harper, A. M. (1968). The role of tyramine in the aetiology of migraine, and related studies on the cerebral and extracerebral circulations. Headache, 8, 84-97.

Hauptmann, A. (1946). Capillaries in the finger nail fold in patients with neurosis, epilepsy and migraine. Archives of Neurology and Psychiatry, 56, 631-642.

Rompel, H., and Bauermeister, P. W. (1970). Aetiology of migraine and prevention with carbamazepine (Tegretol): results of a double-blind, cross-over study. South African Medical Journal, 44, 75-80.

Schumacher, G. A., and Wolff, H. G. (1941). Experimental studies on headache. Archives of Neurology and Psychiatry, 45, 199-214. 